\title{
Los PAisajes Costeros INTERPRETADOS DESDE LA RiPARIA. REFLEXIONES SOBRE EL GOLFO DE CÁDIZ A FINALES DE LA EDAD MEDIA
}

\section{THE COASTAL LANDSCAPES INTERPRETED FROM THE RIPARIA. REFLECTIONS ON THE GULF OF CADIZ IN THE LATE MidDle AGES}

\author{
EMILIO MARTÍN GUTIÉRREZ \\ emilio.martin@uca.es
}

UNIVERSIDAD DE CÁDIZ ${ }^{1}$

http://dx.doi.org/10.25267/Riparia sup.2019.i2.03

\section{RESUMEN}

Aplicando el concepto Riparia a los estudios históricos, en este trabajo se reflexiona sobre los paisajes costeros en el Golfo de Cádiz a finales de la Edad Media. Se presta atención a los corrales de pesca, a la incidencia de los eventos catastróficos y a la representación de la línea de costa tomando en consideración el complejo portuario de Cádiz.

Palabras Claves: Paisajes costeros. Riparia. Golfo de Cádiz. Finales de la Edad Media.

\footnotetext{
1 Profesor Titular de Universidad. Historia Medieval. Departamento de Historia, Geografía y Filosofía. Facultad de Filosofía y Letras, Avda. Gómez Ulla, s/n, 11003, Cádiz, ESPAÑA.

E. Martín Gutiérrez, «Los paisajes costeros interpretados desde la Riparia. Reflexiones sobre el Golfo de Cádiz a finales de la Edad Media», Suplemento RIPARIA 2 (2019), 47-79.
} 
E. MARTÍN GUTIÉRREZ

\section{Abstract}

Applying the Riparia concept to historical studies, this work reflects on coastal landscapes in the Gulf of Cádiz in the late Middle Ages. Attention is given to the fishing pens, to the incidence of catastrophic events and to the representation of the coast line taking into consideration the port complex of Cádiz.

KEY WORDs: Coastal landscapes. Riparia, Gulf of Cádiz, The late Middle Ages. 
"Lo escrito se va haciendo, se esculpe y se moldea a sí mismo, en un material casi tan intangible como las moléculas de agua en suspensión" Antonio Muñoz Molina, Un andar solitario entre la gente, 99

\section{La interacción sociedad-medio ambiente interpretada desde la Riparia}

Durante los años sesenta del siglo XVI Anton van den Wyngaerde visitó varias ciudades españolas. Felipe II le había encargado la decoración del palacio de El Pardo y el Alcázar de Madrid, así como la realización de "un inventario descriptivo de las más importantes ciudades de España". Las setenta y dos vistas conservadas constituyen un apartado notable de la nueva imagen geográfica que se estaba perfilando del mundo, buscando reflejar con "precisión detallistas los edificios y monumentos, situándolos en su territorio circundante". Es así como interpreto la panorámica del «Porto de Santa María».

Fechada en 1567, en esta vista de la ciudad se superponen diferentes paisajes: las explotaciones salineras en la margen izquierda del Guadalete, las embarcaciones surtas en la bahía gaditana y en el río entre su desembocadura y la Sierra de San Cristóbal, la localidad de El Puerto, con los edificios más notables, y sus alrededores ${ }^{3}$.

2 J. Maderuelo, El paisaje. Génesis de un concepto, Abada, Madrid 2006, 276-281. Las citas en las páginas 277 y 279.

3 IBIDEM. 


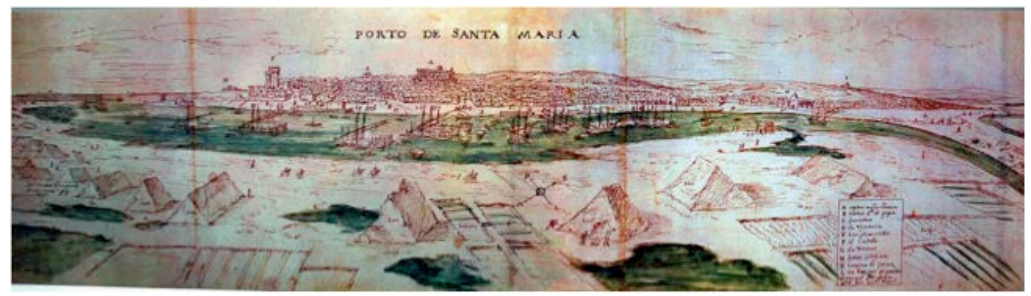

Vista del Porto de Santa María

Esta imagen aporta información sobre dos líneas argumentales, imbricadas entre sí, que de un tiempo a esta parte me interesan como línea de investigación: la interacción de la sociedad con el medio ambiente, con especial mención al aprovechamiento de los recursos naturales vinculados a la Riparia, y el crecimiento económico de la bahía gaditana y su inclusión en una red comercial y financiera en el Golfo de Cádiz. Aunque ésta no fue una región marginal durante la época andalusí ${ }^{5}$, durante el siglo XV experimentó un incremento notable en el tráfico comercial. En los últimos años el análisis de la expansión europea de los siglos XV y XVI se viene efectuando en clave regional ${ }^{6}$. La identificación de regiones mediterráneas y atlánticas interconectadas sostiene la idea de un crecimiento económico polinuclear: como afirma Bartolomé Yun, no se trataría de pensar los espacios europeos en clave centro-periferia sino en individualizar las diferentes regiones dentro de una globalidad $^{7}$.

4 M. A. Caballero Sánchez, «Las vistas de El Puerto de Santa María en 1567 de Anton van den Wyngaerde: pautas interpretativas y análisis de contenido», Revista de Historia de El Puerto, 41, $2^{\circ}$ semestre (2008), 109-147.

5 C. PiCARD, L'Océan Atlantique musulman. De la conquête arabe à l'époque almohade. Navigation et mise en valeur des côtes d'al-Andalus et du Maghreb occidental (Portugal-EspagneMaroc), Maisonneuve \& Larose-Éditions UNESCO, Paris 1997. A. ANDRADE, «A importância da linha costeira na estruturação do Reino medieval português. Algumas reflexões», Historia. Instituciones. Documentos, 35, (2008), 9-24.

${ }^{6}$ S. R. EPSTEIN, Libertad y crecimiento. El desarrollo de los estados y de los mercados en Europa, 1300-1750, Universitat, Valéncia 2009, 62-63.

7 B. Yun, Marte contra Minerva. El precio del Imperio Español. C. 1450-1600, Crítica, Barcelona, 2004, 103-104.

«Los paisajes costeros interpretados desde la Riparia. Reflexiones sobre...» 


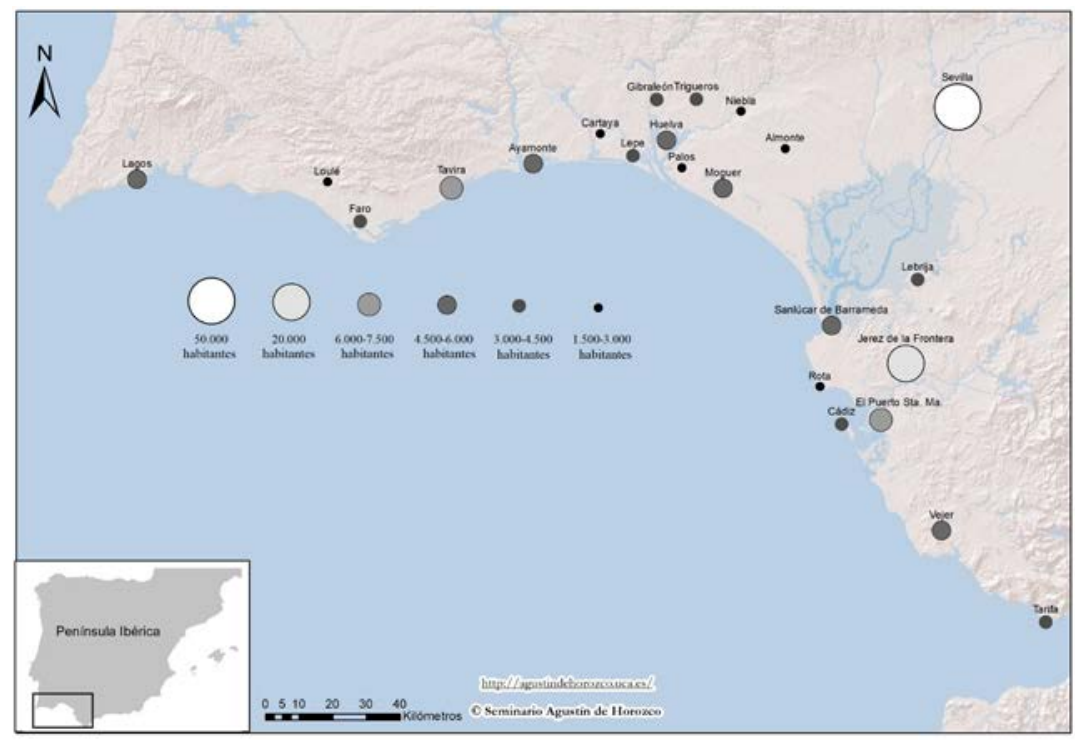

Cartografía Golfo de Cádiz. Finales de la Edad Media ${ }^{8}$

La costa andaluza del Golfo de Cádiz se divide en el sector onubense y en el gaditano. El primero, que se corresponde con la cuenca del Guadalquivir, cuenta con litorales arenosos, playas, marismas, acantilados bajos y flechas litorales como El Rompido y Doñana. En el gaditano hay dos zonas bien diferenciadas: mientras que en la parte más cercana al estuario del Guadalquivir las bahías y ensenadas se entremezclan con una costa lineal, en el Estrecho de Gibraltar, las estribaciones de las cordilleras Béticas tienen su reflejo en costas acantiladas y pequeñas ensenadas?. Las características morfodinámicas de este paisaje costero deben ser puestas en estrecha relación con el asentamiento de poblaciones, el aprovechamiento de sus recursos naturales o la creación de instalaciones para la navegación. Un

8 Cartografía SIG elaborada en el Seminario Agustín de Horozco a cargo del Dr. Enrique Ruiz Pilares.

9 J. Benavente, F. J. Gracia, L. Del Río, G. Anfuso, A. Rodríguez Ramírez, «Caracterización morfodinámica de las playas españolas del Golfo de Cádiz», Boletín Geológico y Minero, 126, 2-3, (2015), 409-426, 413. 
ejemplo de lo que acabo de señalar fue la relación entre la evolución de los estuarios y desembocaduras del Guadiana y del Guadalquivir y la apuesta por las explotaciones salineras ${ }^{10}$.

Pero no hay que fijar la atención exclusivamente en el litoral. Su imbricación con el interior -un hinterland imprescindible ya que la tierra fue la fuente de riqueza en las sociedades preindustriales -aporta una clave importante a retener en el discurso. En este sentido, el caso de la abortada fundación de una población en Tempul es altamente significativo y me sirve para ilustrar lo que quiero decir. En 1548 el concejo de Jerez respondía de forma negativa a la petición del comendador de Santiago Hernando Padilla Dávila que pretendía fundar una población en Tempul ubicada en el término jerezano.

"Otrosy, articula y prueba que si el dicho río [Guadalete. Sic: debería decir Guadalcacín] se sacase para haser los regadíos como la parte contraria dize, demás de la pérdida de los ganados, como está dicho en el capítulo antes deste, la nabegaçión del Portal se perdería ques el puerto donde desenvarcan las mercadurías que a la dicha çiudad [Jerez] traen y por donde se sacan los esquilmos que en aquella çiudad se coxen ques pan, bino, azeyte, aba y garbanço y todo lo demás que por aquel puerto se saca de que redunda grandísimo venefiçio a las rentas reales de su magestad. La qual dicha nabegaçión se perdería si el río lo ataxasen por arriba con sacallo para haser los regadíos porque las mareas no rebalsarían el agua que de riba biene. Y no abiendo rebalsamiento de agua los nabíos no podrían entrar al muelle a tomar las cargas y perder será la nabegaçión y lo que de aquí interesa a su magestad y sus rentas" 11 .

\footnotetext{
${ }^{10}$ L. Menanteau, «Géohistoire des salines côtières du Guadiana et du Guadalquivir», en L. Menanteau (Dir.), Sels et salines de l'Europe atlantique, Presses Universitaires, Rennes 2018, 151-165.

11 AMJF, Archivo Histórico Reservado. Traslado del pleito de Hernando de Padilla sobre población de Tempul. Año 1548. Cajón 11, n 3. Sin foliar.
}

«Los paisajes costeros interpretados desde la Riparia. Reflexiones sobre...» 


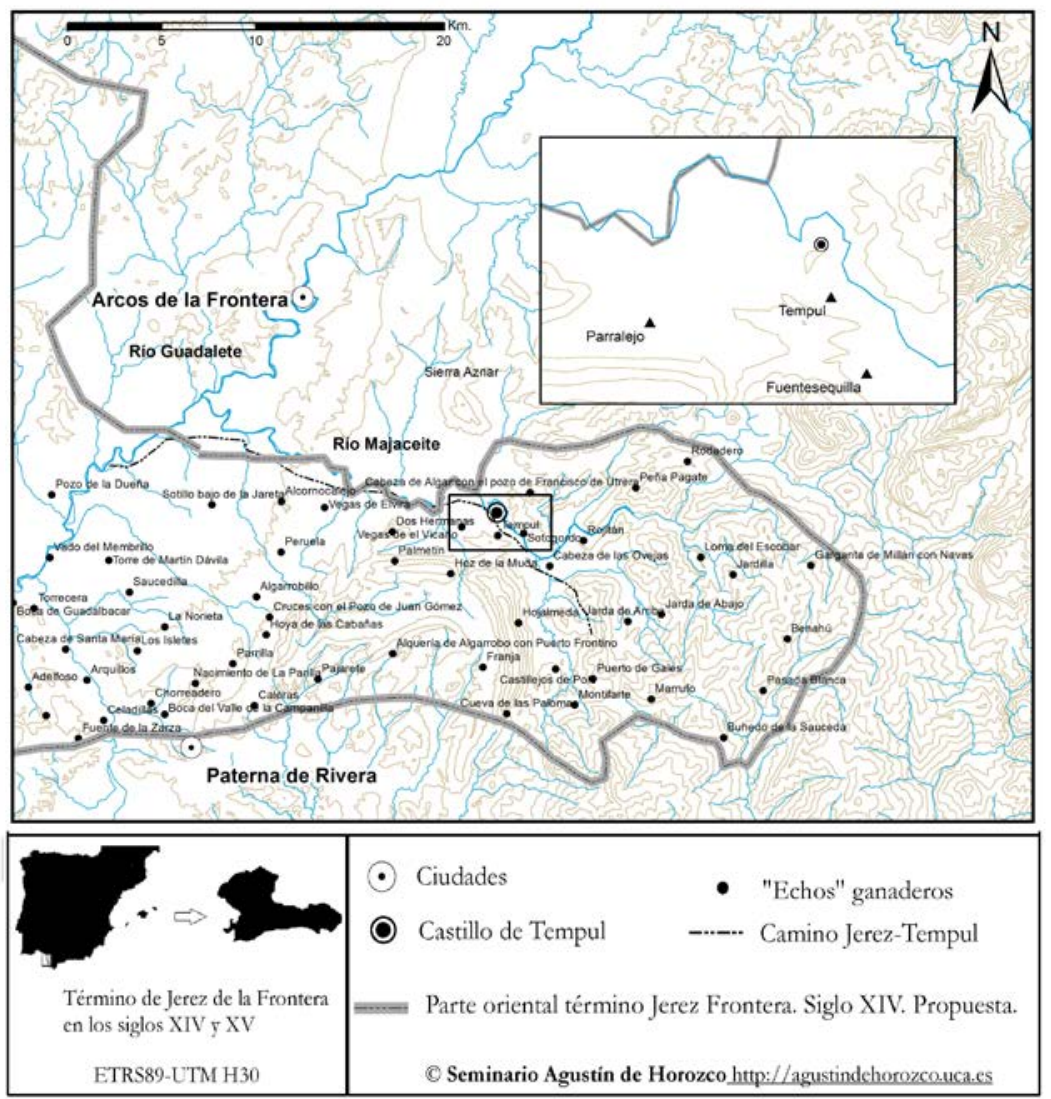

El proyecto de la fundación de Tempul en el término de Jerez de la Frontera ${ }^{12}$

Los argumentos del concejo de Jerez apuntaban hacia las consecuencias negativas que tendrían la creación de una población. La inevitable reordenación del paisaje -pérdida de espacios pecuarios y creación de un sistema de regadío aprovechando el manantial de Tempul y los recursos hídricos del entorno -también repercutiría sobre la navegación y el trasiego de

12 Cartografía SIG elaborada en el Seminario Agustín de Horozco a cargo del Dr. Enrique José Ruiz Pilares. 
mercancías en el muelle del Portal, las actividades comerciales e, incluso, en la fiscalidad de la corona ${ }^{13}$.

En los últimos años vengo analizando esta problemática adaptando el concepto «Riparia»-que procede del ámbito de la ecología -a los estudios históricos. Esta narrativa toma como referencia los estudios de Ella Hermon centrados en la sociedad romana. Su propuesta agrupa interpretaciones ambientales y culturales en una visión holística de la gestión del agua ${ }^{14}$. Desde el «Seminario Agustín de Horozco» de la Universidad de Cádiz estoy analizando el aprovechamiento de los recursos naturales en bosques, ríos, arroyos, humedales o marismas ${ }^{15}$. El objetivo es comprender los mecanismos a través de los cuales la sociedad desde una ciudad o desde una villa -fue organizando sus correspondientes paisajes y cuál fue el tipo de aprovechamiento de sus recursos naturales. En los casos analizados los ecosistemas anteriormente aludidos no fueron espacios marginales, estando incluidos dentro del sistema económico.

Esta narrativa entronca con otras investigaciones que se están llevando a cabo en los últimos años. Así, por ejemplo, a la

13 E. Martín Gutiérrez, «El agua en Tempul a finales de la Edad Media», en L. LAGÓSTENA BARRIOS (Ed.), Lacus autem idem et stagnus, ubi inmensa aqua convenit. Estudios históricos sobre humedales en la Bética (II), Seminario Agustín de Horozco, Cádiz 2016, 67 84.

14 E. HERMON, «Les interactions société-environnement: L'évolution diachronique des concepts», Caesarodunum, XXXIX, (2005), 23-40. Desde otros presupuestos, la gestión del agua también se viene aplicando a la época medieval: A. MALPICA CuELlo, «Le trasformazioni agricole e l'avanzata cristiana nella Penisola Iberica», en I paesaggi agrari d'Europa (secoli XIII-XV). Pistoia, 16-19 maggio 2013, Viella, Roma 2015, 101-125.

15 E. MARTín GutiÉRreZ, «Paisajes palustres entre la desembocadura del Guadalquivir y el Guadalete durante los siglos XIII al XV», en A. MAlPICA Cuello (Ed.), Zonas búmedas en Andalucía medieval. Inicio de un debate, Alhulia, Granada 2017, 13-49. «El agua en Tempul. «El aprovechamiento de humedales y marismas en el término de Cádiz: segunda mitad del siglo XIII », en L. LAGÓSTENA BARRIOS (Ed.), Qui lacus aquae stagna paludes sunt... Estudios históricos sobre bumedales en la Bética, Seminario Agustín de Horozco, Cádiz 2015, 121-147. "Interacción sociedad y medio ambiente. Siglos XIII al XV. El entorno de la laguna de los Tollos (Andalucía Occidental)», Studia Historica. Historia Medieval, 32, (2014), 103-130. «Sistemas socio-ecológicos » En prensa.

«Los paisajes costeros interpretados desde la Riparia. Reflexiones sobre...» 
hora de analizar las transformaciones de la costa en los actuales Países Bajos (en Rijnland) durante los siglos altomedievales, William TeBrake afirmaba que cada asentamiento con sus tierras y aguas constituía « una unidad de explotación ambiental » de la que los habitantes adquirían los recursos necesarios para la vida ${ }^{16}$. Estudios, como el anteriormente señalado, permiten sostener que esta línea de investigación -el estudio de los paisajes desde una clave ambientalista -está sólidamente asentada. Una prueba de lo que acabo de decir son las recientes síntesis - me refiero a las elaboradas por Richard C. Hoffmann, Riccardo Rao o Fabrice Mouthon -que abordan esta problemática ${ }^{17}$.

Vinculado, por tanto, a esta narrativa, en este artículo apuntaré algunas reflexiones sobre los paisajes costeros interpretados desde la Riparia. Me referiré, en concreto, a los corrales de pesca, como ejemplo del aprovechamiento de los recursos naturales, a la incidencia de los eventos catastróficos y, finalmente, a la representación de la costa a partir de los complejos portuarios con especial mención al caso de Cádiz. Las ideas que expondré a continuación encuentran acomodo en un planteamiento global que he desarrollado de forma más extensa en otra publicación ${ }^{18}$.

\section{Un tipo de aprovechamiento de los recursos naturales costeros: los corrales de pesca}

En la Península Ibérica la dinámica expansiva de la sociedad feudal se sustentó en un proceso de «agrarización». Con este neologismo -parecido al de «cerealización » utilizado por Robert Bartlett a la hora de explicar esta misma política expansiva

\footnotetext{
16 W. H. TeBrake, Medieval Frontier. Culture and ecology in Rijinland, University Press, Texas 1985, 141.

17 R. C. Hoffmann, An Environmental History of Medieval Europe, University Press, Cambridge 2015. R. RAO, I paesaggi dell'Italia medievale, Carocci Editore, Roma 2015. F. Mouthon, Le sourire de Prométhée.

${ }^{18}$ E. MARTín GuTIÉRREZ, «Sistemas socio-ecológicos», En prensa.
} 
en Europa Occidental ${ }^{19}$-Josep Torró pone el acento en la apuesta por el cereal, «la viña y otros cultivos regionalmente significativos, como los olivos en Andalucía y Mallorca $»^{20}$. Durante el siglo XV esta dinámica expansiva se fue manifestando con mayor intensidad en la costa del Golfo de Cádiz. En efecto, junto a un incremento de esta «agrarización» y al aprovechamiento de los recursos naturales de bosques y montañas, sobresalieron las actividades pesqueras, las instalaciones de almadrabas, las roturaciones de marismas y la consiguiente creación de explotaciones salineras o los corrales de pesca. Por este motivo he planteado la posibilidad de que el aprovechamiento de los recursos naturales costeros también deban ser tenidos en cuenta a la hora de reflexionar sobre esta "agrarización" tardía -entendida como una manifestación del carácter expansivo de la sociedad feudal -durante el siglo XV en el Golfo de Cádiz ${ }^{21}$.

Tomando en consideración este planteamiento, en esta ocasión quisiera centrarme en un tipo de aprovechamiento de los recursos naturales costeros: los corrales de pesca construidos con piedras. En el «Diccionario histórico de las artes de pesca» publicado en 1791, Antonio Sánchez Reguart dedicaba un apartado a este tipo de arte:

"Sea de la clase que fuere, un corral, para construirle, es menester elegir playa cuyo terreno incline ó se halle en pendiente hacia el mar; de manera que, a la baxada de la marea, quede sin agua. Semejantes parages son sin disputa los mejores para este efecto; pero también se pueden construir en los que después de baxado el mar queda algo de agua, como que los pescadores entran en ella con redes pequeñas para coger los

\footnotetext{
19 R. BARTLETT, La formación de Europa. Conquista, civilización y cambio cultural, 950-1350, Universitat, Valéncia 2003, 208-213

20 J. TORRÓ, «Paisajes de Frontera: conquistas cristianas y transformaciones agrarias (siglos XII al XIV)», Edad Media. Revista de Historia, En prensa.

21 E. MARTín GuTIÉRREZ, «Sistemas socio-ecológicos», En prensa.

«Los paisajes costeros interpretados desde la Riparia. Reflexiones sobre...»
} 
peces. Este no es inconveniente, pues que algunos de propósito hacen hoyos dentro de sus corrales, de modo que allí se junte toda la pesca que llega a quedar encerrada" 22 .

Los corrales de pesca son ecosistemas con formas de vida vegetal y animal adaptadas al entorno. Constituyen un ejemplo magnífico de la interacción de la sociedad con el medio formando parte del paisaje costero.

"La combinación de factores ecológicos como la escasa profundidad, la luminosidad, el movimiento intermareal -cuyas oscilaciones generan cambios recurrentes en la temperatura, la oxigenación o la salinidad del agua $-\mathrm{O}$ el sustrato rocoso poroso, constituyen un ecosistema que permite el desarrollo de diversas formas de vida vegetal y animal que se han adaptado a este entorno" 23 .

Con estas palabras David Florido del Corral reflexionaba sobre esta técnica tradicional y en torno a las instalaciones conservadas en la costa de Andalucía Occidental. Su estudio aporta ideas muy interesantes que incluyo en mi investigación como puede observarse en las siguientes líneas.

En las Tablas 1 y 2 incluyo solamente aquellos corrales de pesca - un total de dieciocho -que he localizado en la bibliografía y en la documentación de archivo, ubicados en el estuario del Guadalquivir y en la Bahía de Cádiz. Su datación -entre finales del siglo XIV y durante el XVI -hace referencia al momento en el que aparece en la documentación y no, por tanto, a su origen. Esto es importante ya que, como comentaré posteriormente, su

22 A. SÁnchez Reguart, Diccionario histórico de las artes de la pesca nacional, 5 vols., Madrid 1791, vol II, 319.

23 D. Florido Del CorRaL, «Corrales, una técnica de pesca tradicional en Andalucía», en D. Bernal Casasola (Ed), Pescar con arte. Fenicios y romanos en el origen de los aparejos andaluces. Catálogo de la exposición Baelo Claudia, diciembre 2011-julio 2012, Cádiz, 2011, 65$91,78$. 
existencia bien pudiese ser anterior a la fecha señalada en las tablas. Por este motivo, es más que probable que el listado pudiera ser ampliado con otras referencias documentales circunscritas siempre a este marco cronológico.

\begin{tabular}{|c|c|c|c|}
\hline \multicolumn{4}{|c|}{ Sanlúcar de Barrameda } \\
\hline Nombre & Propietario & Adquisición & Año \\
\hline Gallego & Duque Medina Sidonia & - & $1450^{24}$ \\
\hline Corvina & Convento $\mathrm{S}^{\mathrm{a}} \mathrm{M}^{\mathrm{a}}$ de Barrameda & $\begin{array}{l}\text { Donación } \\
\text { Juan Ponce de } \\
\text { León }\end{array}$ & 1455 \\
\hline Montijos & Convento de $\mathrm{S}^{\mathrm{a}} \mathrm{M}^{\mathrm{a}}$ de Barrameda & $\begin{array}{l}\text { Donación } \\
\text { Juan Ponce de } \\
\text { León }\end{array}$ & 1466 \\
\hline \multicolumn{4}{|c|}{ Chipiona } \\
\hline- & Convento $N^{a} S^{a}$ de Regla & $\begin{array}{l}\text { Donación Pedro } \\
\text { Ponce de León }\end{array}$ & 1399 \\
\hline- & Convento $\mathrm{N}^{a} \mathrm{~S}^{\mathrm{a}}$ de Regla & $\begin{array}{l}\text { Donación Pedro } \\
\text { Ponce de León }\end{array}$ & 1399 \\
\hline Alamín & $\begin{array}{l}\text { Pedro Camacho de Villavicencio, el } \\
\text { Rico. Jerez } \\
\text { Iglesia San Salvador. Jerez }\end{array}$ & - & 1507 \\
\hline ¿Sulaver? & $\begin{array}{l}\text { Pedro Camacho de Villavicencio, el } \\
\text { Rico. Jerez } \\
\text { Ana López, viuda de Alonso Núñez } \\
\text { de Villavicencio. Jerez } \\
\text { Juan Bernal del Espino. Jerez } \\
\text { Diego Clemente }\end{array}$ & - & 1507 \\
\hline Pelaio & Convento $\mathrm{N}^{a} \mathrm{~S}^{\mathrm{a}}$ de Regla & $\begin{array}{l}\text { Donación } \\
\text { Francisco Pavón. } \\
\text { Chipiona }\end{array}$ & 1560 \\
\hline
\end{tabular}

Tabla 1. Corrales de pesca. Estuario del Guadalquivir. Finales XIV-XVI25.

${ }^{24}$ En 1566 el propietario de este corral de pesca es el monasterio de Santa María de Barrameda. D. Florido DEL CORRAL, «Corrales, una técnica de pesca», 73.

25 A. Moreno Ollero, Sanlúcar de Barrameda a fines de la Edad Media, Diputación, Cádiz 1983, 106. IDEM, «El convento de Nuestra Señora de Regla en Chipiona (Cádiz). Formación de su patrimonio», Cuadernos de Estudios Medievales, VIII-IX, (1980), 193-202, 194 y 196 D. Florido DEL CORRAL, «Corrales, una técnica de pesca», 73. E. MARTín GutiÉRreZ, «Paisajes imaginados y paisajes reales a finales de la Edad Media. Humedales y marismas en las comarcas gaditanas», en $\mathrm{M}^{a}$ I. DEL VAL VALDIVIESO

«Los paisajes costeros interpretados desde la Riparia. Reflexiones sobre...» 


\begin{tabular}{|c|c|c|c|}
\hline \multicolumn{4}{|c|}{ Cádiz } \\
\hline Nombre & Propietario & Tipo de adquisición & Año \\
\hline Pedro Bernal & $\begin{array}{l}\text { Gutiérrez González } \\
\text { Canónigo de Cádiz }\end{array}$ & $\begin{array}{l}\text { Compra a Diego de } \\
\text { Estopiñán, jerezano }\end{array}$ & 1478 \\
\hline Pedro Bernal & $\begin{array}{l}\text { Gutiérrez González } \\
\text { Canónigo de Cádiz }\end{array}$ & Compra a Sancho Zurita & $1478 ?$ \\
\hline San Sebastián & $\begin{array}{l}\text { Esteban Rajón } \\
\text { Canónigo de Cádiz }\end{array}$ & $\begin{array}{l}\text { Compra a Alonso Romero } \\
\text { y su mujer, jerezanos }\end{array}$ & 1511 \\
\hline \multicolumn{4}{|c|}{ Rota } \\
\hline - & $\begin{array}{l}\text { Convento Nuestra } \\
\text { Señora de Regla } \\
\end{array}$ & $\begin{array}{l}\text { Donación Pedro Ponce de } \\
\text { León }\end{array}$ & 1399 \\
\hline - & $\begin{array}{l}\text { Convento Nuestra } \\
\text { Señora de Regla }\end{array}$ & $\begin{array}{l}\text { Donación Pedro Ponce de } \\
\text { León }\end{array}$ & 1399 \\
\hline En Medio & $\begin{array}{l}\text { Alonso de Suazo } \\
\text { Jurado. Jerez }\end{array}$ & - & 1511 \\
\hline - & $\begin{array}{l}\text { Alonso de Suazo } \\
\text { Jurado. Jerez }\end{array}$ & - & 1511 \\
\hline - & Duque de Arcos & $\begin{array}{l}\text { Arrendador Rodrigo } \\
\text { Caballero. Vecino de Rota }\end{array}$ & 1533 \\
\hline Encima & $\begin{array}{l}\text { Cofradía del Santísimo } \\
\text { Sacramento de Rota }\end{array}$ & & 1581 \\
\hline San Clemente & $\begin{array}{l}\text { Hospital de la Santa } \\
\text { Misericordia de Rota }\end{array}$ & & $\begin{array}{l}\text { Finales } \\
\text { XVI }\end{array}$ \\
\hline \multicolumn{4}{|c|}{ E1 Puerto de Santa María } \\
\hline Almejas & - & - & $\begin{array}{l}\text { Inicio } \\
\text { XVI }\end{array}$ \\
\hline
\end{tabular}

Tabla 2. Corrales de pesca. Babia de Cádiæ. Finales XIV-XV $T^{26}$.

(Coord.), El agua en el imaginario medieval. Los reinos ibéricos en la Baja Edad Media, Univesitat, Alacant 2016, 18-40, 34-35.

26 P. Antón Solé y M. Ravina Martín, Catálogo de documentos medievales del Archivo Catedralicio de Cádiz 1263-1500, Ayuntamiento, Cádiz 1975, 97. F. Devís MárQuez, «Acerca de las fortunas gaditanas en torno al año 1500: el ejemplo de los miembros del capítulo catedralicio», Cádiz en su Historia. III Jornadas de Historia de Cádiz. Abril 1984, Caja de Ahorros, Cádiz 1984, 23-45, 35. J. J. Iglesias RoDríGuEZ, « Las industrias del mar en el litoral bajo andaluz a comienzos de la Edad Moderna », Revista de Historia de El Puerto, 28, (2002), 11-23, 17. J. J. López AmAdor y J. A. Ruiz GiL « Arqueología y etnografía de los recursos marinos en El Puerto de Santa María (Cádiz) », Revista de Historia de El Puerto, 44, $1^{\text {er }}$ semestre, (2010), 9-57, 26. D. Florido Del Corral, "Corrales, una técnica de pesca », 73. E. Ruiz Pilares, «El paisaje pesquero de Jerez 
Un tema muy interesante es el relativo al origen de los corrales de pesca ${ }^{27}$. Tomando en consideración los casos de Chipiona, Antonio Ramos ha abierto una línea de investigación que debe ser tenida en cuenta. En estas pesquerías convivieron, por un lado, los corrales viejos de jábegas de tradición andalusí y, por otro, los nuevos corrales de cerco de tradición castellana. En su opinión los antiguos corrales de jábega fueron construidos por pescadores beréberes, asentados en la zona tras la conquista, que llevaron a la práctica sus conocimientos de las artes pesqueras adquiridos en sus lugares de origen en la costa africana ${ }^{28}$.

$\mathrm{Al}$ igual que ocurría con otras actividades económicas, en la puesta en funcionamiento de los corrales de pesca participaron diversos sectores de la sociedad andaluza de finales de la Edad Media. Desde este punto de vista, "representan formas concretas de apropiación política del entorno" lo que implica -según David del Corral -que estén inscritos "en relaciones sociales de producción, que llegar a ser del todo relaciones de poder, formas de apropiación territorial, modelos de gestión del recurso" ${ }^{29}$.

A finales de la Edad Media los propietarios fueron las instituciones religiosas, los señores laicos y los grandes propietarios urbanos. Un buen ejemplo podría ser el corral del Gallego en Sanlúcar de Barrameda, propiedad del duque de Medina Sidonia, que proporcionó las rentas, incluidas en la Tabla 3 , durante las primeras décadas del siglo XVI.

de la Frontera a finales de la Edad Media: caladeros, flota, distribución y consumo ", Historia. Instituciones. Documentos, 45 (2018), 377-405, 385-386.

27 D. Florido DEL CORRAL, «Corrales, una técnica de pesca», 70-72.

28 "Los corrales viejos de jábega se originan y desarrollan en la Pesquería de Chipiona, a partir del originario Corral Trapo, sucedido por los corrales Cabito y después Longueras. Posteriormente, los nuevos corrales de cerco se iniciaron en la Pesquería de Cuba, con los dos corrales madre y arquetípicos que son el Corral Hondo y el Corral Camarón.” A. Ramos Millán, "Una hermenéutica de la arqueología del mar. Las pesquerías bereberes de corrales de piedra de la Chipiona andalusí (Cádiz)", Antiquitas, 28 (2016), 135-164, 146-147.

${ }^{29}$ D. Florido Del CorRAL, «Corrales, una técnica de pesca», 68.

«Los paisajes costeros interpretados desde la Riparia. Reflexiones sobre...» 


\begin{tabular}{|c|c|c|}
\hline Año & Renta (en maravedíes) & Porcentaje sobre el total recaudado \\
\hline 1513 & 7.833 & $5,26 \%(4.125 .872)$ \\
\hline 1515 & 16.500 & $2,29 \%(3.792 .867)$ \\
\hline 1525 & 12.000 & $1,42 \%(1.714 .674)$ \\
\hline 1528 & 14.000 & $2,70 \%(3.793 .059)$ \\
\hline 1530 & 15.000 & $1,89 \%(2.839 .500)$ \\
\hline 1535 & 11.000 & $3,87 \%(4.258 .855)$ \\
\hline
\end{tabular}

Tabla 3. Rentas de la Casa Ducal de Medina Sidonia en Sanlúcar de Barrameda. El corral del Gallego ${ }^{30}$.

En otros casos la propiedad estaba compartida entre varios propietarios urbanos como ocurría en Chipiona. Así, mientras que el corral del Alamín era propiedad del veinticuatro jerezano Pedro Camacho de Villavicencio «el Rico»y de la iglesia jerezana de San Salvador, el de Sulaver pertenecía a los jerezanos Ana López, viuda de Alonso Núñez de Villavicencio, Juan Bernal del Espino, Diego Clemente y al ya citado Pedro Camacho $^{31}$. Lo mismo ocurría con el corral de pesca de Pero Bernal en Cádiz. Aunque en este caso hubo un movimiento interesante. Dividido en cuatro partes, en 1478 el canónigo de Cádiz Gutiérrez González compraba la cuarta parte al jerezano Diego de Estopiñán por 35.000 maravedíes. Esta operación económica se completaba otra que él había realizado con anterioridad al adquirir otra cuarta parte del también jerezano Sancho de Zurita ${ }^{32}$. El precio alcanzado -35.000 maravedíes -es un índice notable, como en su momento se encargó de subrayar Federico Devís, de su alta rentabilidad ${ }^{33}$. En Cádiz también se ubicaba el corral de pesca de San Sebastián dividido en cuatro partes. En 1511 el canónigo de la iglesia catedral de Cádiz Esteban Rajón compraba una cuarta parte a los jerezanos Alonso

\footnotetext{
30 A. Moreno Ollero, Sanlúcar de Barrameda, 79.

31 E. MARTín GutiÉRreZ, «Paisajes imaginados y paisajes reales», 34-35.

32 P. Antón Solé y M. Ravina Martín, Catálogo de documentos medievales, 97.

33 F. Devís MÁrqueZ, «Acerca de las fortunas gaditanas en torno al año 1500, 35. R. SÁnCHEZ SAus, Cádiz en la época medieval, en F. J. Lomas SALmONTE y R. SÁnCHEZ SAus, Entre la leyenda y el olvido. Épocas Antigua y Media, Historia de Cádiz, vol. I, Sílex, Madrid 1991, 256.
} 
Romero y su mujer. En esta ocasión el precio fue sólo de 2.000 maravedíes ${ }^{34}$.

El sistema de explotación era mediante arrendamiento ${ }^{35}$. En la documentación de archivo he localizado algunos ejemplos significativos. El 30 de diciembre de 1507 el jerezano Pedro Camacho de Villavicencio «el Rico » arrendaba la tercera parte del corral del Alamín en Chipiona a Alonso Fernando el Lobo vecino de esta localidad durante tres años a razón de 3.700 maravedíes y dos lisas anuales ${ }^{36}$. Ese mismo día la iglesia jerezana de San Salvador arrendaba a Pedro de Cazalla, vecino de Chipiona, las dos terceras parte de dicho corral. Este arrendamiento quedaba formalizado por tiempo de tres años a razón de 3.800 maravedíes y 4 lisas anuales ${ }^{37}$.

En 1511 el jurado Alonso de Suazo, vecino de Jerez en la collación de San Mateos, arrendaba a Bartolomé Martín, vecino de la villa de Rota "un corral de tomar pescado e tres mareas de otro corral que se dise el Corral del Medio". Este corral se ubicaba en Rota "en que bate e baña la mar." Según se especificaba en el contrato, se arrendaba este corral "e tres mareas" durante un año desde el día de Todos los Santos. Se arrienda "con todas sus entradas e salidas e vsos e costumbres e seruidumbres". La renta quedaba fijada en 3.500 maravedíes que debía pagarse de la siguiente forma: la tercera parte el día de Carnestolendas de 1512 y el resto el día de San Miguel de $1512^{38}$.

\footnotetext{
${ }^{34}$ F. Devís MÁrQueZ, «Acerca de las fortunas gaditanas en torno al año 1500, 38 y 45. 35 "Los catadores eran los encargados de la explotación del corral, mediante un contrato de arriendo con el propietario." En este sentido "Catar el corral significa tener el privilegio de realizar su pesca, de hacer el despesque." D. Florido DEL CORRAL, «Corrales, una técnica de pesca», 84.

36 E. MARTÍN GutiÉRREZ, «Paisajes imaginados y paisajes reales», 34-35.

37 AMJF, PN, 30 de diciembre de 1507, fols. 9r-9v.

38 AMJF, PN, Año 1511, fols. 603v-604v. E. Ruiz Pilares, «El paisaje pesquero», 386.

«Los paisajes costeros interpretados desde la Riparia. Reflexiones sobre...»
} 
Entre 1533 y 1536 Rodrigo Caballero, avecindado en Rota, ponía en explotación un corral de pesca, ubicado en esta localidad, pagando 6.000 maravedíes anuales al propietario el duque de Arcos. Esta cantidad -que, como se encarga de señalar el documento, era « por la renta del corral de pesquería que en mi quedó rematada por los dichos quatro años»-se abonaría a finales del mes de agosto de cada año al duque o a su recaudador en la citada villa ${ }^{39}$.

No es mucha la información que he conseguido recabar de los arrendatarios anteriormente citados: Alonso Fernando el Lobo, Pedro de Cazalla, Bartolomé Martín o Rodrigo Caballero. En el Padrón de Vecinos de la villa de Chipiona, fechado en 1523, se incluyen los nombres de dos miembros de la familia Cazalla: Gonzalo de Cazalla, cuyas propiedades incluía "una casa de paja de su morada" y 7 aranzadas de viñas, y Juan de Cazalla que, aunque en aquel momento vivía en una casa de alquiler, declaraba que tenía "unas casas suyas, el palacio de teja y lo demás de paja" y 25 aranzadas de viñas ${ }^{40}$. Podría ser factible que Pedro -que aparece en el contrato de arrendamiento de 1507 hubiese formado parte de esta familia incluida en este padrón de vecinos. Con independencia de este caso, sospecho -aunque sólo es una mera intuición -que los arrendatarios localizados en la documentación notarial debían formar parte de la oligarquía local. Dispongo de poca información documental que aporte luz sobre el sistema de trabajo en los corrales de pesca a finales de la Edad Media. En las condiciones del contrato de arrendamiento del corral de En Medio de Rota del año 1511, aludido con anterioridad, se incluía la siguiente fórmula:

\footnotetext{
39 AHN, Sección Nobleza, OSUNA, C. 1609, D. 1-87 271 Documentación relativa al arrendamiento y cobro de rentas de las villas de Rota y Chipiona, fols. 1-2.

40 A. Franco Silva, "Población y reparto de la propiedad en Chipiona en el primer cuarto del siglo XVI", en B. Arizaga Bolumburu et al (Eds.), Mundos Medievales. Espacios, sociedades y poder. Homenaje al profesor José Ángel García de Cortázary Ruiz de Aguirre, Universidad, 2 vols., Santander 2012, vol. II, 1319-1338, 1135.
} 
"En tal manera que sy vos el dicho Bartolomé Martín [arrendatario del corral de pesca] adobarades el dicho corral a su costa que non me pagueys más de tres mil marauedíes de renta por el dicho corral e tres mareal. E sy yo lo adobare que todavía vos deys e paguéys los dichos tres mil e quinientos marauedíes a los dichos plasos [...] Yten, que vos el dicho Bartolomé Martín seays obligado en fyn del dicho año de me dexar el dicho corral e mareas moliente e corriente so pena que me deys e paguéys pena de çinco mil marauedíes" ${ }^{41}$.

No se debe olvidar que la propia estructura del corral de pesca necesitaba "un permanente trabajo de vigilancia y reparación" que atendiese los efectos derivados del $\operatorname{mar}^{42}$. Se trata, por tanto, de una línea de investigación que podría ser interesante desarrollar en próximos trabajos.

\section{Algunas reflexiones sobre la incidencia de los eventos catastróficos en la costa}

"Y a poco rato de haber sosegado lo trémoro [sic] de la tierra, estando en los Oficios Divinos los fieles en la Iglesia, y celebrándose la misa mayor, se oyó un ruidoso estruendo hacia el mar, que llenó de pavor y miedo a los habitantes, los que solicitando la causa de este insulto, repararon haberse alterado el mar y salido de su curso con tal furia, que las olas o, por mejor decir, rollos de mar, que no sólo subieron por cima de los barrancos con bastante furia, inundando las calles y playa, sí también que arrancando quasi de cimientos todos los corrales de pesquería, sembró con sus piedras las calles que venían envueltas en el desordenado oleaje, cuya intespetuosa noticia alteró los animos de los fieles, de tal suerte que salieron los que en la Iglesia estaban".

41 AMJF, PN, Año 1511, fols. 603v-604v.

42 D. Florido DEL CORRAL, «Corrales, una técnica de pesca», 84.

«Los paisajes costeros interpretados desde la Riparia. Reflexiones sobre...» 
Este texto es una parte de la descripción emitida por el gobernador de Sanlúcar de Barrameda de los efectos ocasionados por el tsunami de 1755 que arrasó los corrales de pesca ubicados en la costa de Chipiona ${ }^{43}$. En efecto, los eventos costeros de carácter catastróficos -entre los que sobresalen los temporales, los huracanes como el de 1671 en Cádiz ${ }^{44}$ y los tsunamis como el de 1755 causado por el terremoto de Lisboa ${ }^{45}$-también deben ser tenidos en cuenta en esta reflexión. En el Golfo de Cádiz el registro sedimentario de temporales se localiza en playas y cordones litorales como en Sancti Petri, en la flecha de Valdelagrana o en la costa de Conil ${ }^{46}$. De un tiempo a esta parte, los historiadores también están aportando sus lecturas mediante la búsqueda de información en archivos, participando, de esta forma, en esta problemática ${ }^{47}$.

Al igual que Venecia - pienso, por ejemplo, en trabajos como los de Elisabeth Crouzet-Pavan o Elly Hermon ${ }^{48}$-Cádiz

43 J. M. MARTínez SOLARES, Los efectos en España del terremoto de Lisboa (1 de noviembre de 1755), Ministerio de Fomento. Dirección General del Instituto Geográfico Nacional. Monografía 19, Madrid 2001, 282.

44 Los efectos del huracán de 1671, según se recogen en las Actas Capitulares de la ciudad, pueden leerse en Ma P. Ruiz Nieto-Guerrero, J. J. Jiménez Mata, Historia urbana de Cádiz: Génesis y formación de una ciudad moderna, Colegio Oficial de Arquitectos, Cádiz 2016, 80-82.

45 J. A, Aparicio Florido, 1755. El maremoto que viene, QBook, Cádiz 2017. L. DE LUQUE, «El impacto de eventos catastróficos costeros en el litoral del Golfo de Cádiz», Revista Atlántica-Mediterránea de Prebistoria y Arqueología Social, 10 (2008), 131-153. J. M. Martínez Solares, «Tsunamis en el contexto de la península Ibérica y del Mediterráneo», Enseñanza de las Ciencias de la Tierra, 13.1, (2005), 52-59.

46 L. DE LUQUE, «El impacto de eventos catastróficos», 132 y 137-142.

47 M. Matheus, G. Piccinni, G. Pinto, G. M. Varanini (A cura di), Le calamità ambientali nel Tardo Medioevo europeo: realtà, percezioni, relazioni. Atti del XII convegno del Centro di Studi sulla civiltà del tardo Medioevo. S. Miniato, 31 maggio-2 gingno 2008, University Press, Firenze 2010.

48 E. Crouzet-Pavan, «Une histoire du risque. Venise et les périls de mer», en M. Matheus, G. Piccinni, G. Pinto, G. M. VAranini (A cura di), Le calamità ambientali nel Tardo Medioevo europeo, 127-158. E. HERMON, «Les interactions société-environnement 
también podría ser un caso paradigmático de estudio: la ciudad encontró su defensa natural en el mar, pero, al mismo tiempo, tuvo que enfrentarse al mar. Por ejemplo, la incidencia de los temporales en el camino o Arrecife, los agobios explicitados hasta la extenuación por el ingeniero italiano Juan Bautista Calvi en lo tocante a la cimentación de los primeros baluartes defensivos en la década de los cincuenta del siglo XVI o la destrucción del faro de Cádiz en $1587^{49}$.

Aunque aún no contamos con una investigación de base centrada en esta problemática para la época medieval, se trata de un caso de estudio que merece ser tenido en cuenta. Aún siendo consciente que el registro arqueológico debería aporta información, en la documentación de archivo hay noticias dispersas que permiten hilvanar un discurso centrado en la interacción de la sociedad gaditana con el medio ${ }^{50}$. En las cuentas del marqués de Cádiz de 1486 se alude a un temporal que provocó la caída de la Torre que se estaba construyendo en la almadraba de Hércules ${ }^{51}$. Esta escueta referencia podría ponerse en relación con otros datos sueltos. En 1487 el deán de la catedral de Cádiz Esteban Rajón presentaba nueve artículos ante el obispo de Ávila fray Hernando de Talavera, juez nombrado por el papa Inocencio VIII para delimitar los términos de las diócesis y

dans la perspective des milieux ripariense: le cas de la République de Venise », en E. Hermon, A. WATElet (Dirs.), Riparia, un patrimoine culturel. La gestion intégrée des bords de l'eau. Actes de l'atelier Savoirs et pratiques de gestion intégrée des bords de l'eau. Riparia, Sudbury, 12-14 avril 2012, BAR, Oxford 2014, 129-136.

49 V. Fernández Cano, Las defensas de Cádiz en la Edad Moderna, Escuela de Estudios Hispanoamericanos, Sevilla 1973, 7-14. A. DE Horozco, Historia de Cádiz, A. Morgado García (Ed.), Universidad, Cádiz 2001, 210.

${ }^{50} \mathrm{Al}$ analizar el núcleo urbano Rafael Sánchez -basándose en las palabras del cronista gaditano Agustín de Horozco -reconocía la posibilidad de que la villa cristiana: "ocupase una extensión algo mayor de lo que hoy es visible en el barrio del Pópulo [...] De ser así el avance del mar, que a fines de la Edad Media y durante el XVI amenazaba a la misma Catedral, habría afectado previamente a una parte del caserío, el ubicado más hacia el Sur”, R. SÁNCHEZ SAus, Cádiz. Cádiz en la época medieval, 206.

51 AHN, Sección Osuna, Leg. 1622, Año 1486, Cuentas de Lope de Palma, recaudador de don Rodrigo Ponce de León, marqués de Cádiz, fol. 10.

«Los paisajes costeros interpretados desde la Riparia. Reflexiones sobre...» 
obispados conquistados a los musulmanes. En uno de ellos describía la catedral de Cádiz:

"La iglesia de Cádiz es de la mar tan maltratada que sy en breve no es socorrida con grandes ayudas, según la ha tenido alrededor de ella y de las casas obispales, presto caerá" ${ }^{52}$.

Estas palabras pueden ponerse en relación con el siguiente dato: en el año 1500 Esteban Rajón compraba un solar ubicado junto a unas casas que habían pertenecido al canónigo Diego Sánchez de Argumedo y que también había adquirido. Aunque el precio del solar fue de 50.000 maravedíes, realmente se trató -en palabras de Federico Devís - de «una donación de la ciudad a cambio de 50.000 maravedíes de ayuda para la construcción de un muro que dio Rajón a petición del concejo. Dicho muro protegería, por la zona del Vendaval, las casas del deán ${ }^{53}$. El dato es interesante porque muestra una actuación concreta del concejo gaditano en las inmediaciones de la catedral y del caserío anexo. El concejo gaditano contó con el apoyo explícito de unos de los miembros destacado del cabildo catedralicio. Aunque desconozco la entidad de este muro de contención, la cantidad desembolsada permite pensar que tuvo que tener alguna consideración. Sin embargo, los mismos problemas, u otros similares, continuaron reproduciéndose. Por ejemplo, entre 1565 y 1587, coincidiendo con el mandato del obispo García de Haro, la ciudad consiguió que el obispado construyese en la «muralla frontera a la Iglesia Mayor un rompeolas, arruinado en gran parte con su sucesor Gómez de Figueroa, al producirse un derrumbamiento que causó la muerte de algunos servidores del obispo» ${ }^{54}$.

\footnotetext{
52 P. Antón Solé y M. Ravina Martín, Catálogo de documentos medievales, 102.

53 F. Devís MÁrqueZ, «Acerca de las fortunas gaditanas», 44-45. El perfil del deán Esteban Rajón fue dibujado por J. SÁnCHEZ HERrero, Cádiz. La ciudad medieval y cristiana (1260-1525), Caja de Ahorros, Córdoba 19862, 262-266 y 269-272.

54 V. FERnández CANO, Las defensas de Cádiz, 102-103.
} 
Como decía con anterioridad, este tema de investigación apenas ha sido analizado por los medievalistas. Una ausencia que no deja de ser sorprendente ya que la región del Golfo de Cádiz es un espacio idóneo para profundizar en esta problemática.

\section{La representación de la costa a partir de los complejos portuarios: el caso de Cádiz}

Los complejos portuarios permiten visualizar la conexión entre el paisaje costero y las decisiones tomadas por los agentes políticos. Un caso significativo fue Algeciras: la decadencia de las atarazanas de Sevilla en el 914 coincidió con la reactivación de las instalaciones de Algeciras por 'Abd al-Rahman III en su enfrentamiento con Ibn Hafsun; la destrucción de esta ciudad por Muhammad V de Granada en 1378/1379 tuvo su reflejo en la reactivación de otras instalaciones portuarias en el ámbito del Estrecho de Gibraltar ${ }^{55}$.

¿Cómo fue percibida la costa del Golfo de Cádiz entre los siglos XIV y XV? La representación de la costa es un elemento clave. Según los trabajos de Isabel del Val, en las crónicas bajomedievales los paisajes marítimos y marismeños aparecen como metáfora para describir las características de los monarcas y como semblanza de las costumbres y placeres de los reyes ${ }^{56}$. Ahora bien, si se desciende a los detalles de los hitos costeros, los portulanos contienen descripciones de la costa «desde la cubierta » de las embarcaciones ${ }^{57}$. Su proliferación es una prueba

\footnotetext{
55 E. Martín GutiÉrrez, «El Estrecho de Gibraltar durante el siglo XIV: medio ambiente y redes comerciales en Algeciras», Revista del CEHGR, 30 (2018), 51-69.

${ }^{56} \mathrm{M}^{\mathrm{a}} \mathrm{I}$. DEL VAL VALDivieso, «Agua y paisaje en las crónicas castellanas de la Baja Edad Media», en I. Czeguhn, C. Möller, Y. Quesada Morillas, J. A. Pérez Juan Wasser-Wege-Wissen auf der iberischen Halbinsel, Berliner Schriften zur Rechtsgeschichte, 8, (2019), 285-304, 293-299.

57 M. Bochaca Y B. Arízaga Bolúmburu, «Conocimientos náuticos y representaciones del mar en la Baja Edad Media: el ejemplo del Atlántico próximo», en Ma I. Del VAl VAldivieso (Ed.), La percepción del agua en la Edad Media, Universidad, Alicante 2015, 101-110, 106-109
}

«Los paisajes costeros interpretados desde la Riparia. Reflexiones sobre...» 
más del interés de los comerciantes por la región del Golfo de Cádiz ${ }^{58}$.

El complejo portuario de la bahía gaditana incluía muelles, embarcaderos, atarazanas, faros y una red defensiva. El nivel de información de cada uno de estos elementos es desigual $^{59}$. Este complejo portuario se adecuaba a las características morfodinámicas del medio: playas, islas, ríos, arroyos, esteros y marismas surcadas por un complejo entramado de caños y canales; y, obviamente, la bahía, propiamente dicha, dividida en dos ámbitos diferenciados: la exterior y la interior ${ }^{60}$.

Aunque la información de los Portulanos es muy valiosa, no está exenta de dificultades en lo tocante a la localización de la toponimia menor. Me voy a referir a un ejemplo concreto. En el siglo XV en el «Portolano del Mediterraneo» se representaba el

58 V. MuÑoz GómeZ, «Puertos, abras, cabos e islas: la topografía medieval de la costa atlántica de Andalucía a través de las cartas portulanas (ss. XIV-XVI)», en E. AZNAR VAllejo, R. J. GONZÁlez ZALACAín (Coords.), De mar a mar. Los puertos castellanos en la Baja Edad Media, Universidad, La Laguna 2015, 179-211.

59 Sobre el complejo portuario: R. J. GonZÁlez ZALACAín, «De puerto a puerto. Las relaciones entre los puertos de la Bahía de Cádiz (siglos XV-XVI)», en E. AZNAR VAllejo, R. J. González Zalacaín (Coords.), De mar a mar, 147-177. L. MÁrQuez Carmona y C. Alonso Villalobos, «El sistema portuario de la bahía de Cádiz en época moderna a través de la cartografía histórica», en M-R. GARCía HuRTADO Y O. REY CASTElaO (Eds.), Fronteras de agua. Las ciudades portuarias y su universo cultural (Siglos $X I V$-XXI), Universidade, Santiago de Compostela 2016, 181-195, 187. Sobre el sistema defensivo: V. FernándeZ CANO, Las defensas de Cádir.

60 "Divídese esta bahía en dos senos; el mayor y primero -que principalmente se llama bahía -es entre esta ciudad [Cádiz] y la villa del gran Puerto de Santa María. Su circuito casi igualmente redondo, de cuatro a cinco leguas en contorno; dos de través y como legua y media de largo. La entrada tiene derechamente al poniente tan espaciosa y larga como legua y media y lo más angosto de ella es lo que cae en medio del baluarte San Felipe en Cádiz y la ermita de Santa Catalina y torreón que está en ella en término del Puerto. Del agua de la bahía que corre del Poniente al Levante, se hace el otro seno y más seguro puerto y para entrar el agua en él se estrecha la bahía tanto como un cuarto de legua, entre dos puntos una la Matagorda, tierra de Puerto Real, otra El Puntal que está en la isla donde se ha hecho otro baluarte de cuatro años a esta parte." A. DE Horozco, Historia de Cádiz, 219-220. 
perfil costero gaditano desde el mar con especial mención a los puntos elevados:

"Chades à buon porto per tucti tenpi da la locanda da levante; per contra alla terra puoi stare anchora co anchora in fondo di VII passi. La chonoscença di Chades si è una montagna alta fra terra e tonda. E chiamasi loccho di Piero Garsia, chome testa tra grecho e levante. E va alla sua via e trovite [sic] Chades, e volti la punta da maestro e non ti achostare troppo per cierte secche che vi sono; quando non [vai] dritco [sic] al porto lassa due terçi della terra ferma" 61 .

En las cartografías de la bahía del siglo XVIII -como en la de Henry Michelot «Plan de la Baye et Rade de Cadis et des Environs » de 1730 -se especificaba que las «marques qu'il faut tenir pour entrer en la Baye de Cadis » eran el campanario de la iglesia de Puerto Real y Medina Sidonia ${ }^{62}$. Esta información podría completarse con un portulano del Mediterráneo de 1760 donde se señalaba que la entrada a la bahía gaditana debía efectuarse « enfilando el campanario de la iglesia de la población de Puerto Real con la de Medina Sidonia ${ }^{63}$.

61 R. GonZÁlez Arévalo, «La costa del reino de Sevilla en la documentación náutica italiana (siglo XV)», Universidad, Granada 2009, 301-318, 308.

${ }^{62}$ Las mismas indicaciones en la cartografía "Baye et Rade de Cadis" fechada en torno a 1764. R. MARTínez LÓPEZ (Ed.), Un mar para la Historia de Cádiæ: cartografía y estampas de la biblioteca de D. Federico Joly Höhr (Siglos XVI-XIX), Ayuntamiento, Cádiz 2000, 117 y 125.

63 Portulan de la mer Méditerranée ou le vray guide des pilotes costiers: dans le que l'on verra la veritabile maniere de naviguer le long des Côtes d'Espagne, Catalogne, Provence, Italie, les Isles d'Yvice, Mayorque, Corse, Sicile \& autres, Amsterdam, 1760, p. 12. Citado en L. MÁrQueZ Carmona y C. Alonso Villalobos, «El sistema portuario de la bahía de Cádiz en época moderna a través de la cartografía histórica», en M-R. GARCíA HuRTADO y O. REY CASTELAO (Eds.), Fronteras de agua, 181-195, 184.

«Los paisajes costeros interpretados desde la Riparia. Reflexiones sobre...» 


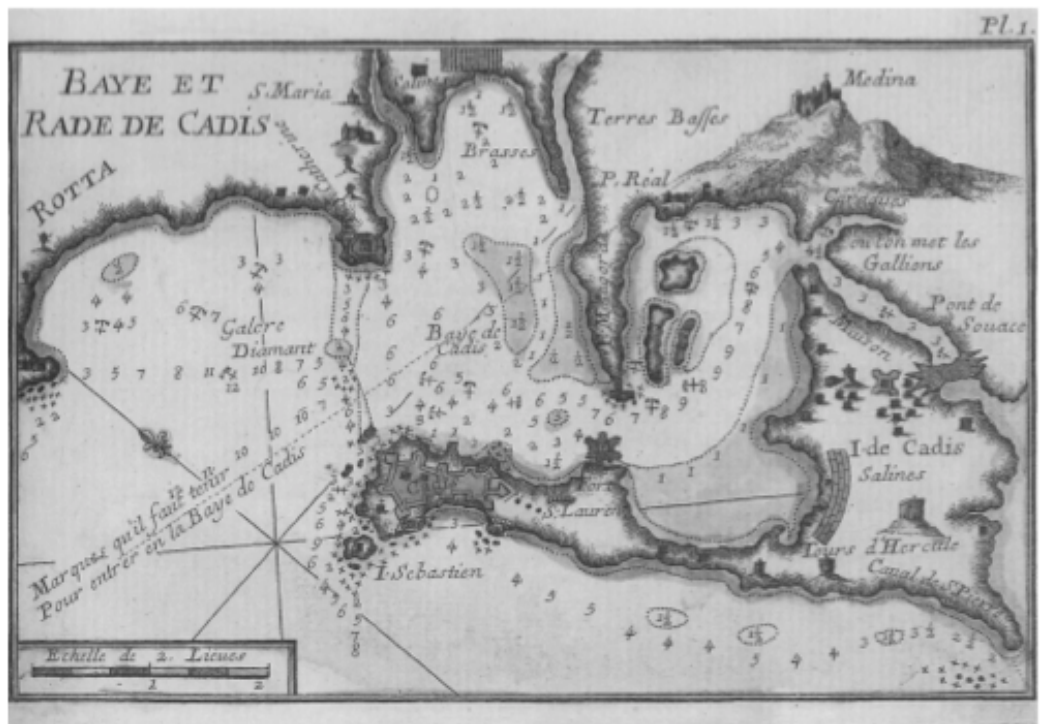

Baye et Rade de Cadis, circa $1764^{64}$

La localidad de Medina Sidonia, visible desde el mar, se ubica en un altozano. Estas indicaciones servían para salvar los bajos rocosos y los bancos de arenas -Punta del Sur, Punta de la Nao, Bajos de Chapitel, Bajo de Las Puercas, Bajos del Diamante y Galera, Arrecifes de Punta Candor -ubicados a la entrada de la bahía. La montaña de Medina Sidonia es visible tanto desde la bahía como a lo largo del cabo de Roche y hasta la punta de San Sebastián ${ }^{65}$. Así pues, podría ser factible relacionar la mención a una «montagna alta fra terra e tonda» con Medina Sidonia. Sin embargo, resta aún sin explicar de manera convincente la siguiente frase: «E chiamasi loccho di Piero Garsia, chome testa tra grecho e levante».

${ }^{64}$ R. Martínez López (Ed.), Un mar para la historia de Cádiz. Cartografía y estampas de la Biblioteca de D. Federico Joy Höhr (S. XVI-XIX), Ayuntamiento, Cádiz 2000, 125.

65 Agradezco a Manuel Ángel Gallego Ramírez, marino mercante, las explicaciones dadas sobre este tema. 


\section{Consideraciones finales}

Como decía al principio, la región del Golfo de Cádiz durante el siglo XV merece un estudio detallado. Aunque hasta la fecha no se ha efectuado una síntesis, estoy llevando a cabo algunos trabajos que están aportando los primeros resultados ${ }^{66}$. En este sentido, el estudio de los paisajes rurales y del aprovechamiento de los recursos naturales es otra vía de análisis de la sociedad medieval en tanto creadora de los mismos.

Los estudios geoarqueológicos vienen explicando la configuración y evolución de la costa. El hecho de analizar un paisaje en constante movimiento, como he señalado en alguna ocasión, exige conjugar las transformaciones geológicas y antrópicas ${ }^{67}$. Por citar un único ejemplo, Loïc Ménanteau ha evidenciado la combinación de los factores naturales y antrópicos en los puertos de Palos, Sevilla y Sanlúcar de Barrameda entre los siglos XII y XVI. Si los primeros fueron los causantes de la fuerte dinámica hidro-sedimentaria, los cambios en las técnicas culturales y el aprovechamiento del suelo tras la conquista feudal acentuaron y aceleraron los procesos de sedimentación ${ }^{68}$.

66 E. Martín Gutiérrez, «Sistemas socio-ecológicos» En prensa. E. Martín GuTiÉRreZ, «El Golfo de Cádiz durante el siglo XV: una prospectiva ambiental», Small Cities and Environment (from the Middle Ages to Contemporary Times). Castelo da Vide, 1416/3/2019, En prensa.

${ }^{67}$ E. MARTín GuTIÉRREZ, «Entre la Costa y la Sierra gaditanas. De los paisajes rurales a la interacción sociedad medio ambiente en el siglo XV», Arqueología y Territorio Medieval, 25, (2018), 227-259, 231-234.

${ }^{68}$ L. MENANTEAU, «L'influence des facteurs naturels et anthropiques sur l'évolution des ports de Basse-Andalousie (XIII -XVIe siècles): études de cas (Palos de la Frontera, Séville et Sanlúcar de Barrameda)», en M. Bochaca ET J-L. SARrazin, Ports et littoraux de l'Europe atlantique. Transformations naturelles et aménagements humains (XIVe-XV Te siècles), Presses universitaires, Rennes 2015, 167-187, 185. Hay otros ejemplos interesantes: J. M. Campos Carrasco, «Análisis arqueológico del puerto histórico de Palos de la Frontera», en GonzÁlez de lA Cruz (Coord.), Descubridores de América. Colón, los marinos y los puertos, Silex, Madrid 2012. A. TeIXEIRA, «L'évolution de l'habitat domestique à Ksar Seghir à la fin du Moyen Âge: étude archéologique et conservation d'une maison mérinide-portugaise», en A. TEIXEIRA, En las dos orillas del Estrecho de Gibraltar. Arqueología de Frontera en los siglos XIV-XVI, Universidade, Lisboa-Açores 2016, 29-126.

«Los paisajes costeros interpretados desde la Riparia. Reflexiones sobre...» 
La proximidad al mar -explicación determinista -no tendría porqué haber garantizado el desarrollo de la región del Golfo de Cádiz, al menos, en los niveles en los que éste se produjo. En cambio, diversas estrategias «externas»-la guerra de Castilla contra Granada y la conquista de plazas costeras en el norte de África -e «internas»-fundaciones de pueblos, apuesta por una «agrarización», entidad de los paisajes pecuarios, aprovechamiento de los recursos naturales del litoral -sí propiciaron un impulso notable materializado en un crecimiento económico. Éste favoreció el consumo interno, la inclusión de los productos en el comercio internacional y la adopción de un sistema fiscal complejo acorde con los poderes implicados: el real, el señorial, el eclesiástico y el concejil. En cualquier caso y a pesar de este discurso excesivamente triunfalista, no se deben ocultar la situaciones cercanas a la pobreza o el fuerte endeudamiento que afectó a todos los sectores sociales de la Andalucía del siglo XV y de las primeras décadas del $\mathrm{XVI}^{69}$.

El aprovechamiento de los recursos naturales costeros junto con las explotaciones agropecuarias, los bosques, las montañas, los ríos o los humedales -estuvo en conexión con el crecimiento de las ciudades y villas andaluzas durante el siglo XV. En este planteamiento, la clave ambiental se me antoja fundamental. La idea principal es analizar los paisajes costeros como un sistema socio-ecológico donde el sistema natural y el sistema social están en continuo diálogo e interacción ${ }^{70}$.

${ }_{69}$ M. BorRero FERNÁNDEZ, «Jornaleros y braceros. La pobreza en la sociedad rural bajomedieval», Ricos y pobres: opulencia y desarraigo en el Occidente Medieval. XXXVI Semana de Estudios Medievales. Estella, 20 a 24 de julio de 2009, Navarra, 2010, 323-365. G. PiCcinni, Il banco dell'Ospedale di Santa Maria della Scala e il mercato del denaro nella Siena del Trecento, Pacini Editore, Pisa 2012, 15-45. E. MarTín GuTiÉRreZ, «El Golfo de Cádiz», En Prensa.

70 J. VARGAS-Molina, «Consecuencias del megaproyecto de dragado de profundización en el sistema socio-ecológico del estuario del Guadalquivir, España», Agua y Territorio, 4, Julio-Diciembre, 2014), 23-34, 24-26. E. MARTín GutiÉRrEZ, «Sistemas socioecológicos», En prensa. 


\section{Bibliografía}

A. ANDRADE, "A importância da linha costeira na estruturação do Reino medieval português. Algumas reflexões", Historia. Instituciones. Documentos, 35, (2008), 9-24.

P. Antón Solé y M. RAVInA MARTín, Catálogo de documentos medievales del Archivo Catedralicio de Cádiz. 1263-1500, Cádiz: Ayuntamiento, 1975. J. A, APARICIO Florido, 1755. El maremoto que viene, QBook, Cádiz 2017.

R. BARTLETT, La formación de Europa. Conquista, civilización y cambio cultural, 950-1350, Valéncia: Universitat, 2003.

J. Benavente, F. J. Gracia, L. Del Río, G. Anfuso, A. Rodríguez RAMÍREZ, "Caracterización morfodinámica de las playas españolas del Golfo de Cádiz”, Boletín Geológico y Minero, 126, 2-3, (2015), 409-426.

M. BOCHACA Y B. ARÍZAGA BOLÚMBURU, "Conocimientos náuticos y representaciones del mar en la Baja Edad Media: el ejemplo del Atlántico próximo", Ma I. DEL VAL VALDIVIESO, María Isabel (ed.), La percepción del agua en la Edad Media, Universidad, Alicante, 2015, 101-110.

M. BORRERO FERNÁNDEZ, «Jornaleros y braceros. La pobreza en la sociedad rural bajomedieval», Ricos y pobres: opulencia y desarraigo en el Occidente Medieval. XXXVI Semana de Estudios Medievales. Estella, 20 a 24 de julio de 2009, Navarra, 2010, 323-365.

M. A. Caballero SÁnCHez, "Las vistas de El Puerto de Santa María en 1567 de Anton van den Wyngaerde: pautas interpretativas y análisis de contenido", Revista de Historia de El Puerto, 41, $2^{\circ}$ semestre (2008), 109-147.

J. M. CAmpos CARrasCo, "Análisis arqueológico del puerto histórico de Palos de la Frontera", GONZÁlEZ DE LA CRUZ (Coord.), Descubridores de América. Colón, los marinos y los puertos, Madrid: Silex, 2012. F. CAPRA, La trama de la vida. Una nueva perspectiva de los sistemas vivos, Barcelona: Anagrama, 2015.

E. Crouzet-Pavan, "Une histoire du risque. Venise et les périls de mer”, M. MAtheus, G. Piccinni, G. Pinto, G. M. VARAnini (A cura di) Le calamità ambientali nel Tardo Medioevo europeo: realtà, percezioni, relazioni. Atti del XII convegno del Centro di Studi sulla civiltà del tardo Medioevo. S. Miniato, 31 maggio-2 gingno 2008, Firenze: University Press, 2010, 127-158.

«Los paisajes costeros interpretados desde la Riparia. Reflexiones sobre...» 
F. DEvís MÁRQUEZ, "Acerca de las fortunas gaditanas en torno al año 1500: el ejemplo de los miembros del capítulo catedralicio", Cádiz en su Historia. III Jornadas de Historia de Cádiæ. Abril 1984, Cádiz: Caja de Ahorros, 1984, 23-45.

EPSTEIN, Stephan R., Libertad y crecimiento. El desarrollo de los estados y de los mercados en Europa, 1300-1750, Valéncia: Universitat, 2009.

V. Fernández CANO, Las defensas de Cádiz en la Edad Moderna, Sevilla: Escuela de Estudios Hispanoamericanos, 1973.

D. FLORIDO DEL CORRAL, "Corrales, una técnica de pesca tradicional en Andalucía”, D. Bernal Casasola (Ed), Pescar con arte. Fenicios y romanos en el origen de los aparejos andaluces. Catálogo de la exposición Baelo Claudia, diciembre 2011-julio 2012, Cádiz, 2011, 6591.

A. Franco Silva, "Población y reparto de la propiedad en Chipiona en el primer cuarto del siglo XVI", en B. ARIZAGA BOLUMBURU ET AL (Eds.), Mundos Medievales. Espacios, sociedades y poder. Homenaje al profesor José Ángel García de Cortázar y Ruiz de Aguirre, Universidad, 2 vols., Santander 2012, vol. II, 1319-1338.

R. GonzÁlez ArÉvalo, "La costa del reino de Sevilla en la documentación náutica italiana (siglo XV)", Granada: Universidad, 2009, 301-318.

R. J. GONZÁLEZ ZALACAÍN, "De puerto a puerto. Las relaciones entre los puertos de la Bahía de Cádiz (siglos XV-XVI)", E. AZNAR VALLEjO Y R. J. GONZÁLEZ ZALACAÍN (Coords.), De mar a mar. Los puertos castellanos en la Baja Edad Media, La Laguna: Universidad, 2015, 147-177.

E. HERMON, «Les interactions société-environnement: L'évolution diachronique des concepts», Caesarodunum, XXXIX, (2005), 23-40.

E. HERMON, "Les interactions société-environnement dans la perspective des milieux ripariense: le cas de la République de Venise", E. Hermon, A. WATElet (Dirs.), Riparia, un patrimoine culturel. La gestion intégrée des bords de l'eau. Actes de l'atelier Savoirs et pratiques de gestion intégrée des bords de l'eau. Riparia, Sudbury, 12-14 avril 2012, Oxford: BAR, 2014, 129-136.

R. C. Hoffmann, An Environmental History of Medieval Europe, Cambridge: University Press, 2015.

A. De Horozco, Historia de Cádiæ, A. Morgado García (Ed.), Cádiz: Universidad, 2001. 
J. J. IGLESIAS RodríGUEZ, "Las industrias del mar en el litoral bajo andaluz a comienzos de la Edad Moderna", Revista de Historia de El Puerto, 28, (2002), 11-23.

J. J. LÓPEZ AMADOR Y J. A. RUIZ GIL «Arqueología y etnografía de los recursos marinos en El Puerto de Santa María (Cádiz)», Revista de Historia de El Puerto, 44, $1^{\mathrm{er}}$ semestre, (2010), 9-57.

L. DE LUQUE, "El impacto de eventos catastróficos costeros en el litoral del Golfo de Cádiz", Revista Atlántica-Mediterránea de Prehistoria y Arqueología Social, 10 (2008), 131-153.

J. MAderuelo, Elpaisaje. Génesis de un concepto, Madrid, Abada, 2006.

A. MALPICA CUELLO, «Le trasformazioni agricole e l'avanzata cristiana nella Penisola Iberica», publicado en I paesaggi agrari d'Europa (secoli XIIIXV). Pistoia, 16-19 maggio 2013, Roma, Viella, 2015, 101-125.

L. Márquez Carmona y C. Alonso Villalobos, "El sistema portuario de la bahía de Cádiz en época moderna a través de la cartografía histórica”, M-R. GARCía HURTADO Y O. REY CASTELAO (Eds.), Fronteras de agua. Las ciudades portuarias y su universo cultural (Siglos XIV-XXI), Santiago de Compostela: Universidade, 2016, 181-195.

E. MARTÍN GutiÉRREZ, "El Estrecho de Gibraltar durante el siglo XIV: medio ambiente y redes comerciales en Algeciras", Revista del CEHGR, 30 (2018), 51-69.

E. MARTÍN GuTIÉRREZ, «Entre la Costa y la Sierra gaditanas. De los paisajes rurales a la interacción sociedad medio ambiente en el siglo XV», Arqueología y Territorio Medieval, 25, (2018), 227-259.

E. MARTín GUTIÉRREZ, "Paisajes palustres entre la desembocadura del Guadalquivir y el Guadalete durante los siglos XIII al XV", en A. Malpica Cuello, A. (Ed.), Zonas húmedas en Andalucía medieval. Inicio de un debate, Granada: Alhulia, 2017, 13-49.

E. MARTÍN GUTIÉRREZ, "Paisajes imaginados y paisajes reales a finales de la Edad Media. Humedales y marismas en las comarcas gaditanas", $\mathrm{M}^{\mathrm{a}}$ I. DEL VAL VALDIVIESO (Coord.), El agua en el imaginario medieval. Los reinos ibéricos en la Baja Edad Media, Alacant: Univesitat, 2016, 18-40. E. MARTín GutiÉRrEZ, "El agua en Tempul a finales de la Edad Media”, en L. LAGÓSTENA BARRIOS (Ed.), Lacus autem idem et stagnus, ubi inmensa aqua convenit. Estudios históricos sobre bumedales en la Bética (II), Cádiz: Seminario Agustín de Horozco, 2016, 67-84.

E. MARTÍN GuTIÉRREZ, "El aprovechamiento de humedales y marismas en el término de Cádiz: segunda mitad del siglo XIII", en L. 
LAGÓSTENA BARRIOS (Ed.), Qui lacus aquae stagna paludes sunt... Estudios históricos sobre bumedales en la Bética, Cádiz: Seminario Agustín de Horozco, 2015, 121-147.

E. MARTÍN GUTIÉRREZ, "Interacción sociedad y medio ambiente. Siglos XIII al XV. El entorno de la laguna de los Tollos (Andalucía Occidental)", Studia Historica. Historia Medieval, 32, (2014), 103-130.

E. MARTÍN GUTIÉRREZ, "Sistemas socio-ecológicos. El aprovechamiento de las marismas en la región del Golfo de Cádiz durante el siglo XV", A. MALPICA CuEllo, J. ARIAS GARCía Y G. GARCÍA-CONTRERAS RUIZ (Coords.), Los bumedales como sistemas socioecológicos. Aproximaciones multidisciplinares, Granada: Alhulia, 2019, En prensa.

E. MARTÍN GuTIÉRREZ, «El Golfo de Cádiz durante el siglo XV: una prospectiva ambiental», Small Cities and Environment (from the Middle Ages to Contemporary Times). Castelo da Vide, 14-16/3/2019, En prensa.

R. MARTÍNEZ LÓPEZ (Ed.), Un mar para la Historia de Cádiz: cartografía y estampas de la biblioteca de D. Federico Joly Höhr (Siglos XVI-XIX), Cádiz: Ayuntamiento, 2000.

J. M. MARTínez SOLARES, «Tsunamis en el contexto de la península Ibérica y del Mediterráneo», Enseñanza de las Ciencas de la Tierra, 13.1, (2005), 52-59.

J. M. MARTíNEZ SOLARES, Los efectos en España del terremoto de Lisboa (1 de noviembre de 1755), Ministerio de Fomento. Dirección General del Instituto Geográfico Nacional. Monografía 19, Madrid 2001.

M. Matheus, G. Piccinni, G. Pinto, G. M. VAranini (A cura di), Le calamità ambientali nel Tardo Medioevo europeo: realtà, percezioni, relazioni. Atti del XII convegno del Centro di Studi sulla civiltà del tardo Medioevo. S. Miniato, 31 maggio-2 giugno 2008, Firenze: University Press, 2010.

L. MenATEAU, "Géohistoire des salines côtières du Guadiana et du Guadalquivir", en L. MENATEAU (Dir.), Sels et salines de l'Europe atlantique, Rennes: Presses Universitaires, 2018, 151-165.

L. MENATEAU, "L'influence des facteurs naturels et anthropiques sur l'évolution des ports de Basse-Andalousie (XIII $-\mathrm{XVI}{ }^{\mathrm{e}}$ siècles): études de cas (Palos de la Frontera, Séville et Sanlúcar de Barrameda)", M. BOCHACA, J-L. SARRAZIN, Ports et littoraux de l'Europe atlantique. Transformations naturelles et aménagements bumains (XIV ${ }^{e}-X V T^{e}$ siècles), Rennes: Presses universitaires, 2015, 167-187. 
A. Moreno Ollero, Sanlúcar de Barrameda a fines de la Edad Media, Cádiz: Diputación, 1983.

A. Moreno Ollero, "El convento de Nuestra Señora de Regla en Chipiona (Cádiz). Formación de su patrimonio", Cuadernos de Estudios Medievales, VIII-IX, (1980), 193-202.

F. Mouthon, Le sourire de Prométhée. L’homme et la nature au Moyen Âge, Paris: La Découverte, 2017.

V. MuÑoz GÓMEZ, "Puertos, abras, cabos e islas: la topografía medieval de la costa atlántica de Andalucía a través de las cartas portulanas (ss. XIV-XVI)", E. AZnAR VALlejo, R. J. GONZÁleZ ZALACAÍN (Coord.), De mar a mar. Los puertos castellanos en la Baja Edad Media, La Laguna: Universidad, 2015, 179-211.

C. PICARD, L'Océan Atlantique musulman. De la conquête arabe à l'époque almohade. Navigation et mise en valeur des côtes d'al-Andalus et du Maghreb occidental (Portugal-Espagne-Maroc), Paris: Maisonneuve \& Larose-Éditions UNESCO, 1997.

G. PICCINNI, Il banco dell'Ospedale di Santa Maria della Scala e il mercato del denaro nella Siena del Trecento, Pacini Editore, Pisa 2012.

A. Ramos Millán, "Una hermenéutica de la arqueología del mar. Las pesquerías bereberes de corrales de piedra de la Chipiona andalusí (Cádiz)", ANTIQUITAS, 28 (2016), 135-164.

R. RAO, I paesaggi dell'Italia medievale, Roma: Carocci Editore, 2015.

Ma P. Ruiz Nieto-Guerrero, J. J. Jiménez MATA, Historia urbana de Cádiz. Génesis y formación de una ciudad moderna, Colegio Oficial de Arquitectos, Cádiz 2016.

E. RUIZ PILARES, «El paisaje pesquero de Jerez de la Frontera a finales de la Edad Media: caladeros, flota, distribución y consumo», Historia. Instituciones. Documentos, 45 (2018), 377-405.

W. H. TeBrake, Medieval Frontier. Culture and ecology in Rijinland, Texas: University Press, 1985.

J. SÁnCHEZ HERRERO, La ciudad medieval y cristiana (1260-1525), Córdoba: Caja de Ahorros, $1986^{2}$.

A. SÁnCHEZ REgUART, Diccionario histórico de las artes de la pesca nacional, 5 vols., Madrid 1791.

R. SÁNCHEz SAUS, Cádiz en la época medieval, F. J. LOMAS SALMONTE Y R. SÁnCHez SAus, Entre la leyenda y el olvido. Épocas Antigua y Media, Historia de Cádiz, vol. I, Madrid: Sílex, 1991. 
A. TEIXEIRA, «L'évolution de l'habitat domestique à Ksar Seghir à la fin du Moyen Âge: étude archéologique et conservation d'une maison mérinide - portugaise», A. TEIXEIRA, En las dos orillas del Estrecho de Gibraltar. Arqueología de Frontera en los siglos XIV-XVI, Lisboa-Açores: Universidade, 2016, 29-126.

J. TORRÓ, "Paisajes de Frontera: conquistas cristianas y transformaciones agrarias (siglos XII al XIV)", Edad Media. Revista de Historia, En prensa.

Ma I. DEL VAL VALDIVIESO, “Agua y paisaje en las crónicas castellanas de la Baja Edad Media”, I. CZEGUHN, C. MÖller, Y. QuesadA MORILlas, J. A. PÉREZ JUAN, Wasser-Wege-Wissen auf der iberischen Halbinsel, Berliner Schriften zur Rechtsgeschichte, 8, (2019), 285-304.

J. VARGAS-MOLINA, «Consecuencias del megaproyecto de dragado de profundización en el sistema socio-ecológico del estuario del Guadalquivir, España”, Agua y Territorio, 4, Julio-Diciembre, (2014), 23-34.

B. Yun, Marte contra Minerva. El precio del Imperio Español. C. 1450-1600, Barcelona: Crítica, 2004. 